\title{
Utilização do Alho (Allium sativum L.) como Promotor de Crescimento de Frangos de Corte ${ }^{1}$
}

\author{
Reginaldo de Freitas ${ }^{2}$, José Brandão Fonseca ${ }^{3}$, Rita da Trindade Ribeiro Nobre Soares ${ }^{3}$, \\ Horacio Santiago Rostagno 4 , Paulo Rubens Soares ${ }^{4}$
}

\begin{abstract}
RESUMO - Três experimentos foram conduzidos com o objetivo de avaliar a utilização do alho na alimentação de frangos de corte, como promotor de crescimento. No primeiro experimento, foram utilizados 480 pintos de corte, sexados, distribuídos em seis tratamentos com oito repetições (quatro de machos e quatro de fêmeas), com dez aves cada uma. Os tratamentos foram: ração basal com milho, farelo de soja e fosfato bicálcio (RB1); RB1 + 0,2\% de alho; RB1 + 0,4\% de alho, RB1 + 0,6\% de alho; RB1 + 0,001\% de lincomicina e RB 1 $+0,0025 \%$ de bacitracina de zinco. No segundo experimento, utilizaram-se 240 pintos de corte, sexados, distribuídos em três tratamentos com oito repetições (quatro de machos e quatro de fêmeas) com dez aves cada uma. Os tratamentos foram ração basal com milho, farelo de soja e farinha de carne e ossos (RB2); RB2 + 0,2\% de alho e RB2 + 0,4\% de alho. No terceiro experimento, foram utilizadas 120 pintos de corte (fêmeas), criadas até aos 42 dias de idade, distribuídos em três tratamentos como descrito para o segundo experimento. Em todos os experimentos, foram avaliados consumo de ração, ganho de peso e conversão alimentar. No primeiro e segundo experimentos, avaliouse também o peso de intestino delgado. Em nenhum dos três experimentos, foram observados efeitos significativos dos tratamentos sobre as características avaliadas. As aves apresentaram desempenho normal, sugerindo que as condições nas quais foram desenvolvidas os experimentos não foram adequadas para obter respostas, devido à utilização de promotores de crescimento.
\end{abstract}

Palavras-chave: alho, frangos de corte, promotores de crescimento, rações

\section{Utilization of Garlic (Allium sativum L.) as Growth Promoter of Broilers}

ABSTRACT - Three experiments were carried out to evaluate garlic in broilers diets as growth promoter. In the first experiment 480 one day old chicks, sexed, were distributed in six treatments with eight replicates (four with males and four with females), with ten birds each. The treatments were: basal diet with corn, soybean meal and dicalcium phosphaate (RB1), RB1 + 0.2\% garlic; RB1 + $0.4 \%$ garlic; $\mathrm{RB} 1+0.6 \%$ garlic, $\mathrm{RB} 1+0.01 \%$ lincomicin and RB $1+0.0025 \%$ zinc bacitracin. In the second experiment 240 one day old chicks were distributed in three treatments with eight replicates (four with males and four with females), and ten birds each. The treatments were: basal diet with corn, soybean meal and bone and meat meal (RB2), RB2 + 0.2\% garlic and RB2 + 0.4\%garlic. In the third experiment 120 females broilers were used, raised up to 42 days of age, distributed in three treatments, as described for the second experiment. In all experiments feed intake, weight gain and feed convertion rate were evaluated. In the first and second experiments small intestine weight was also evaluated. There were no significant effects of tratments on the evaluated charactheristics in the three experiments. The birds presented normal performance, suggesting that the conditions they were raised were not suitable to get response due the utilization of growth promotors.

Key Words: broilers, garlic, growth promoters, rations

\section{Introdução}

O interesse pela utilização de antibióticos na alimentação dos animais baseia-se no fato de que eles promovem maior crescimento, melhoram a conversão alimentar e diminuem a mortalidade devido a infecções clínicas e subclínicas. De acordo com CARRILO et al. (1995), estas melhorias são observadas, possivelmente, devido ao controle de microorganismos não identificados e moderadamente patogênicos que residem no trato gastrointestinal.

Várias pesquisas evidenciam o efeito benéfico da utilização de antibióticos na alimentação animal (BERTECHINI e HOSSAN, 1993; ZUANON et al., 1998).

Entretanto, NONBOE (1999) e LAVAL (1999) esclarecem que, na Europa, o uso de antibióticos como aditivos na alimentação animal foi proibido, a partir de 1999, com a justificativa de que há riscos de desenvolvimento de resistência entre os patógenos humanos. No Brasil, há interesse em se identificar

\footnotetext{
${ }^{1}$ Parte da tese de Mestrado do primeiro autor apresentada à Universidade Federal de Viçosa (UFV).

2 Zootecnista.

3 Professores do LZNA/CCTA/Unversidade Estadual do Norte Fluminense (UENF) Av. Alberto Lamego 2000 - Horto Campos dos Goytacazes - RJ. E.mail: rnobre@uenf.br
} 
novos ingredientes que possam substituir os antibióticos, sem perda no desempenho dos animais. Além disso, há uma tendência atual de maior demanda pelos chamados "produtos orgânicos", ou seja, carne de animais sem aditivos que possuam ação antimicrobiana.

O alho (Allium sativum L.) provoca aumento da secreção gástrica, resultando em ação profilática contra infecções microbianas do trato gastrointestinal (DELMING e KOCH, 1974). Em pesquisas conduzidas in vivo e in vitro, foram identificados no alho dois princípios antibacterianos distintos: alicina (CAVALLITO e BAILEY, 1944) e garlicina (MACHADO et al., 1948), ambos de ação predominantemente bacteriostática, que atuam tanto contra bactérias gram-positivas quanto gram-negativas.

$\mathrm{Na}$ literatura, encontram-se referências sobre outros efeitos benéficos do uso do alho na alimentação animal. PESTI (1997) informou que o uso de 3\% de alho em pó resultou em níveis mais baixos de colesterol no plasma, no fígado e nos músculos de peito de frangos de corte.

Estudos conduzidos por DONZELE et al. (1978) e PICOLO et al. (1979) mostraram que o uso de alho em rações de suínos em crescimento resultou em melhorias no ganho de peso e na eficiência alimentar. $\mathrm{O}$ alho poderia ser usado como promotor de crescimento de suínos mesmo por período prolongado até a fase de terminação, sem que as características organolépticas da carne sejam alteradas.

Esta pesquisa foi conduzido com o objetivo de estudar o potencial do alho como aditivo de rações para frangos de corte, comparado com promotores de crescimento, usados tradicionalmente.

\section{Material e Métodos}

Foram realizados três experimentos em baterias metálicas com aquecimento elétrico, com pintos de corte machos e fêmeas, consumindo rações formuladas para conter $21 \%$ de proteína bruta e $2900 \mathrm{kcal}$ de energia metabolizável, sendo suplementadas com DLmetionina, mistura de vitaminas e minerais. As rações basais (RB) foram formuladas de acordo com as exigências preconizadas por ROSTAGNO et al (1992), utilizando fosfato bicálcio (RB1) e farinha de carne e ossos (RB2) (Tabela 1). O preparo do alho utilizado consistiu em descascá-lo e proceder ao amassamento junto com o fubá de milho, que foi usado como veículo. No Experimento 1, com duração de 24 dias, foram utilizados 480 pintos de corte de um
Tabela 1 - Composição das rações basais

Table 1 - Composition of basal diets

\begin{tabular}{|c|c|c|}
\hline $\begin{array}{l}\text { Ingredientes } \\
\text { Ingredients }\end{array}$ & $\begin{array}{c}\text { Ração } \\
\text { basal 1 (RB1) } \\
\text { Basal diet 1 }\end{array}$ & $\begin{array}{c}\text { Ração } \\
\text { basal } 2 \text { (RB2) } \\
\text { Basal diet } 2 \\
\end{array}$ \\
\hline Milho & 61,71 & 64,42 \\
\hline $\begin{array}{l}\text { Corn } \\
\text { Farelo de soja } \\
\text { Soybean meal }\end{array}$ & 34,50 & 27,60 \\
\hline $\begin{array}{l}\text { Farinha de carne e ossos } \\
\text { Meat and bone meal }\end{array}$ & - & 7,11 \\
\hline $\begin{array}{l}\text { Fosfato bicálcico } \\
\text { Dicalcium phosphate }\end{array}$ & 2,14 & - \\
\hline $\begin{array}{l}\text { Calcário } \\
\text { Limestone }\end{array}$ & 0,95 & 0,130 \\
\hline $\begin{array}{l}\text { Sal } \\
\text { Salt }\end{array}$ & 0,30 & 0,40 \\
\hline $\begin{array}{l}\text { DL-Metionina }(99 \%) \\
\text { DL-Methionine-99\% }\end{array}$ & 0,110 & 0,139 \\
\hline $\begin{array}{l}\text { Suplemento vitamínico* } \\
\text { Vitamin supplement }\end{array}$ & 0,100 & 0,100 \\
\hline $\begin{array}{l}\text { Suplemeto mineral } * * \\
\text { Mineral supplement }\end{array}$ & 0,100 & 0,100 \\
\hline Total & 100,00 & 100,00 \\
\hline $\begin{array}{l}\text { Composição calculada } \\
\text { Calculated composition }\end{array}$ & & \\
\hline $\begin{array}{l}\text { Proteína bruta }(\%) \\
\text { Crude protein }\end{array}$ & 21,00 & 21,31 \\
\hline $\begin{array}{l}\text { Metionina + Cistina (\%) } \\
\text { Methionine + Cystine }\end{array}$ & 0,786 & 0,802 \\
\hline $\begin{array}{l}\text { Metionina }(\%) \\
\text { Methionine }\end{array}$ & 0,435 & 0,464 \\
\hline $\begin{array}{l}\text { Cálcio }(\%) \\
\text { Calcium }\end{array}$ & 0,966 & 0,966 \\
\hline $\begin{array}{l}\text { Fósforo disponível (\%) } \\
\text { Available phosphorus }\end{array}$ & 0,484 & 0,494 \\
\hline $\begin{array}{l}\mathrm{EM}(\mathrm{kcal} / \mathrm{kg}) \\
M E\end{array}$ & 2897 & 2960 \\
\hline \multicolumn{3}{|c|}{ 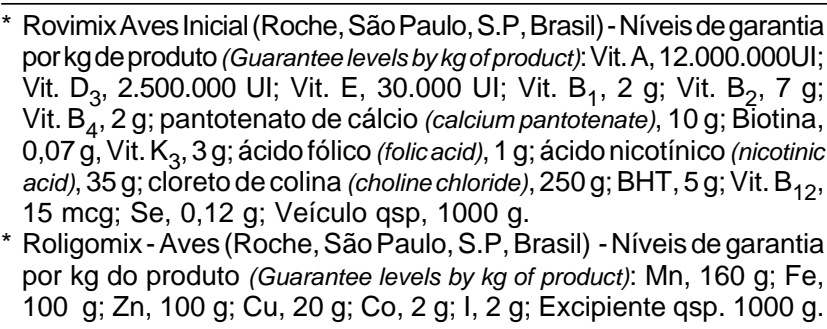 } \\
\hline
\end{tabular}

dia de idade, sexados, distribuídos em seis tratamentos com oito repetições, sendo quatro de machos e quatro de fêmeas, com dez aves por unidade experimental.

Os tratamentos foram os seguintes: RB1, RB1 + $0,2 \%$ de alho, RB1 + 0,4\% de alho, RB1 + 0,6\% de alho, RB1 + 0,0025\% de bacitracina de zinco e $\mathrm{RB} 1+0,001 \%$ de lincomicina.

No segundo experimento, com duração de 21 dias, foram utilizados 240 pintos de corte de um dia de 
idade, sexados, distribuídos em três tratamentos, com oito repetições, sendo quatro de machos e quatro de fêmeas, com dez aves por unidade experimental. Os tratamentos foram: RB2, RB2 + 0,2\% de alho e RB2 $+0,4 \%$ de alho.

No terceiro experimento, com duração de 42 dias, foram utilizados 120 pintos de um dia, fêmeas, distribuídas em três tratamentos com quatro repetições e dez aves por unidade experimental. Os tratamentos foram os mesmos descritos para o segundo experimento.

Nos três experimentos, as características avaliadas foram consumo de ração, ganho de peso e conversão alimentar. Ao final dos dois primeiros experimentos, foram abatidas duas aves de cada unidade experimental, escolhidas aleatoriamente, para avaliar o intestino delgado, de acordo com HENRY et al. (1987). As análises estatísticas das variáveis estudadas nos experimentos foram feitas utilizando o programa SAEG desenvolvido pela UNIVERSIDAE FEDERAL DE VIÇOSA - UFV (1982); para comparação entre médias, utilizou-se o teste de Newman Keuls, adotando-se o nível de 5\% de significância.

\section{Resultados e Discussão}

Os dados de ganho de peso, consumo de ração, conversão alimentar e peso do intestino delgado das aves, no primeiro experimento, são apresentados na Tabela 2. Não houve efeito significativo dos tratamentos $(\mathrm{P}>0,05)$ sobre qualquer uma das variáveis analisadas. Possivelmente, o nível de infestação do trato intestinal por microorganismos não foi suficiente para reduzir o ganho de peso das aves que não receberam alho ou antibiótico (bacitracina de zinco e lincomicina). O ambiente em que as aves foram criadas talvez tenha contribuído para que isso não acontecesse, pois eram baterias metálicas, desinfetadas, localizadas em salas limpas e arejadas. O número de aves alojadas era representativo para o experimento em questão, entretanto, tratava-se de uma população relativamente pequena, quando comparada às populações de aves de criatórios comerciais, onde os desafios sanitários poderiam ser maiores e seria possível observar respostas maiores em relação ao uso de promotores de crescimento.

Segundo Jukes (1949) e Heuser e Morris (1957), citados por CERCOS (1975), os animais livres de patógenos desenvolvem-se melhor que aqueles criados em ambientes contaminados. Estes últimos terão rendimentos semelhantes aos daqueles criados em ambientes livres de patógenos, caso seja usado em suas rações algum promotor de crescimento. WALTON (1990) relatou que a primeira alteração produzida no intestino de animais que consomem promotores de crescimento é diminuição de inflamação da parede intestinal, cujo peso é menor em relação ao animal que não recebeu promotor de crescimento. Neste trabalho, observou-se redução numérica do peso do intestino delgado, devido à utilização do alho ou antibióticos na ração, entretanto, as diferenças observadas não foram significativas.

As características avaliadas no segundo ex-

Tabela 2 - Consumo de ração, ganho de peso, conversão alimentar e peso de intestino delgado das aves, aos 24 dias de idade ( Experimento 1)

Table 2 - Feed intake, weight gain, feed:gain ratio and small intestine weight of birds at 24 days of age (Experiment 1)

\begin{tabular}{|c|c|c|c|c|c|c|c|c|}
\hline \multirow[t]{2}{*}{$\begin{array}{l}\text { Tratamento } \\
\text { Treatment }\end{array}$} & \multicolumn{2}{|c|}{$\begin{array}{c}\text { Consumo de ração }{ }^{1} \\
\text { Feed intake }\end{array}$} & \multicolumn{2}{|c|}{$\begin{array}{c}\text { Ganho de peso } \\
\text { Weight gain }\end{array}$} & \multicolumn{2}{|c|}{$\begin{array}{l}\text { Conversão alimentar } \\
\text { Feed:gain ratio }\end{array}$} & \multicolumn{2}{|c|}{$\begin{array}{c}\text { Peso do intestino delgado }{ }^{1} \\
\text { Small intestine weight }\end{array}$} \\
\hline & (g/ave) & $\mathrm{IC}^{2}$ & G/ave & $\mathrm{IC}^{2}$ & $\mathrm{~g} / \mathrm{g}$ & $\mathrm{IC}^{2}$ & $\mathrm{~g}$ & $\mathrm{IC}^{2}$ \\
\hline $\mathrm{RB}^{3}$ & 1077 & 100 & 794,0 & 100 & 1,44 & 100 & 20,5 & 100 \\
\hline $\begin{array}{l}\text { RB } 1+0,2 \% \text { Alho } \\
\text { RB } 1+0.2 \% \text { Garlic }\end{array}$ & 1100 & 102,1 & 813,0 & 102,4 & 1,40 & 97,2 & 21,0 & 102,4 \\
\hline $\begin{array}{l}\text { RB } 1+0,4 \% \text { Alho } \\
\text { RB } 1+0.4 \% \text { Garlic }\end{array}$ & 1098 & 101,9 & 798,2 & 100,5 & 1,41 & 97,9 & 20,5 & 100 \\
\hline $\begin{array}{l}\text { RB } 1+0,6 \% \text { Alho } \\
\text { RB1+0.6\% Garlic }\end{array}$ & 1098 & 101,9 & 813,0 & 102,4 & 1,43 & 99,3 & 20,5 & 100 \\
\hline RB1 + Bac. de zinco & 1095 & 101,7 & 829,0 & 104,4 & 1,40 & 97,2 & 18,5 & 90,2 \\
\hline RB1+Lincomicina & 1108 & 102,9 & 830,0 & 104,5 & 1,40 & 97,2 & 18,5 & 90,2 \\
\hline
\end{tabular}

\footnotetext{
1 Valores de machos e fêmeas (Males and females values).

2 Índice comparativo (Comparative index).

3 RB1 - Ração basal formulada sem farinha de carne e ossos, com 21,3\% de PB e EM de $2897 \mathrm{kcal} / \mathrm{kg}$ (Basal diet formulated without meat and bone meal, with $21.3 \%$ CP and $2897 \mathrm{ME}$ ).
} 
perimento, bem como os índices comparativos, encontram-se na Tabela 3. Não foram observadas diferenças significativas $(\mathrm{P}>0,05)$ entre os tratamentos (ração basal com alho e sem alho). O ambiente no qual as aves foram criadas pode ter influenciado esses tratamentos, apesar de ter sido incluída na ração básica (RB2) a farinha de carne e ossos, o que poderia representar maior desafio. Se houve alguma contaminação intestinal, esta não chegou a refletir nos índices zootécnicos estudados. Houve alto coeficiente de variação nos dados de peso de intestino delgado, refletindo dificuldades na coleta de amostras mais representativas.

Na Tabela 4 encontram-se os dados de desempenho das aves e os índices comparativos do terceiro experimento. Não houve diferenças estatísticas $(P>0,05)$ entre os dados de desempenho das aves submetidas aos diversos tratamentos, talvez devido às boas condições de criação, como relatadas nos experimentos anteriores, as quais não permitiram a manifestação de desafios que pudessem criar condições para se observar efeitos benéficos significativos do uso do alho e dos promotores de crescimento testados.

Apesar da ausência do desafio ambiental, é importante salientar que, nos experimentos acima mencionados, o alho não funcionou como promotor de crescimento, ou os níveis utilizados não foram suficientes para promover este crescimento.

Tabela 3 - Consumo de ração, ganho de peso, conversão alimentar e peso de intestino delgado das aves, aos 21 dias de idade (Experimento 2)

Table 3 - Feed intake, weight gain, feed:gain ratio and small intestine weight of birds at 21 days of age (Experiment 2)

\begin{tabular}{|c|c|c|c|c|c|c|c|c|}
\hline \multirow[t]{2}{*}{$\begin{array}{l}\text { Tratamento } \\
\text { Treatment }\end{array}$} & \multicolumn{2}{|c|}{$\begin{array}{l}\text { Consumo de ração } \\
\text { Feed intake }\end{array}$} & \multicolumn{2}{|c|}{$\begin{array}{l}\text { Ganho de peso } \\
\text { Weight gain }\end{array}$} & \multicolumn{2}{|c|}{$\begin{array}{l}\text { Conversão alimentar } \\
\text { Feed:gain ratio }\end{array}$} & \multicolumn{2}{|c|}{$\begin{array}{c}\text { Peso do intestino delgado } \\
\text { Small intestine weight }\end{array}$} \\
\hline & (g/ave) & $\mathrm{IC}^{2}$ & g/ave & $\mathrm{IC}^{2}$ & $\mathrm{~g} / \mathrm{g}$ & $\mathrm{IC}^{2}$ & $\mathrm{G}$ & $\mathrm{IC}^{2}$ \\
\hline $\mathrm{RB}^{3}{ }^{3}$ & 855 & 100 & 632 & 100 & 1,47 & 100 & 11,9 & 100 \\
\hline $\begin{array}{l}\mathrm{RB} 2+0,2 \% \text { Alho } \\
R B 2+0.2 \% \text { Garlic }\end{array}$ & 844 & 98,7 & 647 & 102,4 & 1,42 & 96,6 & 10,9 & 91,6 \\
\hline $\begin{array}{l}\mathrm{RB} 2+0,4 \% \text { Alho } \\
R B 2+0.4 \% \text { Garlic }\end{array}$ & 863 & 100,9 & 636 & 100,6 & 1,46 & 99,3 & 10,9 & 91,6 \\
\hline
\end{tabular}

1 Valores de machos e fêmeas (Males and females values).

2 Índice comparativo (Comparative Index).

3 RB2 - Ração basal formulada com farinha de carne e ossos, com $21 \%$ de PB e EM de $2960 \mathrm{kcal} / \mathrm{kg}$ (Basal diet formulated with meat and bone meal, with $21 \%$ CP and 2960 ME).

Tabela 4 - Consumo de ração, ganho de peso e conversão alimentar das fêmeas, aos 42 dias de idade (Experimento 3 ) Table 4 - Means of feed intake, weight gain, and feed:gain ratio of females at 42 days of age (Experiment 3)

\begin{tabular}{|c|c|c|c|c|c|c|}
\hline \multirow[t]{2}{*}{$\begin{array}{l}\text { Tratamento } \\
\text { Treatment }\end{array}$} & \multicolumn{2}{|c|}{$\begin{array}{c}\text { Consumo de ração } \\
\text { Feed } i \text { ntake }\end{array}$} & \multicolumn{2}{|c|}{$\begin{array}{l}\text { Ganho de peso } \\
\text { Weight gain }\end{array}$} & \multicolumn{2}{|c|}{$\begin{array}{c}\text { Conversão alimentar } \\
\text { Feed:gain ratio }\end{array}$} \\
\hline & g/ave & $\mathrm{IC}^{1}$ & g/ave & $\mathrm{IC}^{1}$ & $\mathrm{~g} / \mathrm{g}$ & $\mathrm{IC}^{1}$ \\
\hline $\mathrm{RB} 2$ & 3332,0 & 100,0 & 1581,0 & 100,0 & 2,16 & 100,0 \\
\hline RB2+0,2\% Alho & 3393,0 & 101,8 & 1670,0 & 105,6 & 2,08 & 96,3 \\
\hline$R B 2+0.2 \%$ Garlic & & & & & & \\
\hline RB2+0,4\% Alho & 3299,0 & 99,0 & 1612,0 & 102,0 & 2,09 & 96,8 \\
\hline$R B 2+0.4 \%$ Garlic & & & & & & \\
\hline
\end{tabular}




\section{Conclusões}

Os dados de desempenho de frangos de corte criados em baterias metálicas não permitiram observar efeitos significativos do uso do alho, nos níveis estudados, e dos antibióticos bacitracina de zinco e lincomicina. É possível que o uso destes promotores de crescimento na alimentação de aves criadas em cama e em condições comerciais, em que o nível de microorganismos é maior, possa resultar em maiores benefícios.

\section{Referências Bibliográficas}

BERTECHINI, A.J., HOSSAIN, S.M. Utilização de um tipo de probiótico como promotor de crescimento em rações de frangos de corte. In: CONFERENCIA DE CIÊNCIA E TECNOLOGIA AVÍCOLAS - APINCO, 1993, Santos. Anais... Santos: APINCO, 1993. p.1.

CARRILO, L.M.T., CRUZ, E., RICQUE, D. 1995. Aplication del uso de promotores de crescimento en acuacultura; antibióticos. SOYA NOTÍCIAS. México: Associação Americana de Soja. p.1-11.

CAVALLITO, C.J., BAILEY, J.H. 1944. Allicin, the antibacterial principle of Allium sativum. I. Isolation, physical propertie and bacterial action. J. Amer. Chim. Soc., 66:1950-1951.

CERCOS, A.P. 1975. Los antibióticos y sus aplicaciones agropecuárias. s.1., Salvet. 475p.

DELMING, L., KOCH, H. 1974. Condiments. The stimbiting effect of pepper, curry, paprika, horseradish, garlic nad mustand on gastric acid secretion was examined in the human stomach. Acta Hepato-Gastroenterol, 21(5):377-379.

DONZELE, J.L., COSTA, P.M.A., MELLO, H.V. 1978. Utilização do alho (Allium sativum L.) como estimulante do crescimento de suínos. R. Soc. Bras. Zootec., 7(2):196-207.

HENRY, P.R., AMMERMAN, C.B., CAMPBELL, D.R. et al. 1987. Effect of antibiotics on tissue trace mineral concentration and intestinal tract weight of broiler chicks. Poult. Sci., 66(6):1014-1018.
LAVAL, A. Use of antibiotics in swine production advantages an limits. The problem of antibioresustance. In: IX CONGRESSO BRASILEIRO DE VETERINÁRIOS ESPECIALISTAS EM SUÍNOS, 1999, Belo Horizonte. Anais...Belo Horizonte, 1999. p.119-130.

MACHADO, P.A., GUTIERRES, D.M., CROSS, J.D. et al. 1948. Garlicina - Um novo antibiótico. An. Paulistas Med. Cir., 55(2):9-31.

NONBOE, U. Alternatives to the use of antibiotic growth promoters in farm animal. In: SEMINÁRIO INTERNACIONAL DE SUINOCULTURA, 4, 1999, São Paulo. Anais... São Paulo, 1999. p.46-47.

PESTI, G. 1997. Poultry meat with lower cholesterol. Intern. Poult. Prod., 5(2):31.

PICCOLO, M.G., PEREIRA, A.S., TEIXEIRA, M.A. et al. 1979. Avaliação sensorial da carne de suínos alimentados com rações que continham alho (Allium sativum L.) em substituição a antibióticos. Rev. Ceres, 26(145):268-274.

ROSTAGNO, H.S., SILVA, D.J., COSTA, P.M.A. et al. 1992. Composição de alimentos e exigências nutricionais de ave e suínos; tabelas brasileiras. Viçosa: UFV. 59p.

UNIVERSIDADE FEDERAL DE VIÇOSA - UFV. 1982. SAEGManual de utilização do programa SAEG (Sistema para Análises Estatísticas e Genéticas). Viçosa - MG. 59p.

WALTON, J.R. 1990. Modo de acción de los promotores de crescimento. Ind. Porcina, 10(2):6-11.

ZUANON, J.A.S., FONSECA, J.B., ROSTAGNO, H.S. et al. 1998. Desempenho de frangos de corte alimentados com rações contendo antibiótico e probiótico adicionados isoladamente, associados e em uso sequencial. R. Bras. Zootec., 27(5):994-998.

Recebido em: 05/04/00

Aceito em: 12/12/00 